\title{
Successful Percutaneous Coronary Intervention in a Centenarian Patient With Acute Myocardial Infarction
}

Ki Hong Lee, MD, Myung Ho Jeong, MD, Cho Yun Chung, MD, Donghan Kim, MD, Min Goo Lee, MD, Keun-Ho Park, MD, Doo Sun Sim, MD, Nam Sik Yoon, MD, Hyun Ju Yoon, MD, Kye Hun Kim, MD, Young Joon Hong, MD, Ju Han Kim, MD, Youngkeun Ahn, MD, Jeong Gwan Cho, MD, Jong Chun Park, MD, and Jung Chaee Kang, MD

The Heart Research Center of Chonnam National University Hospital, Cardiovascular Research Institute of Chonnam National University, Gwangju, Korea

Despite an increasing prevalence and burden of disease in the elderly, little is known about the management and outcomes of acute coronary syndromes in this group. We report the case of a 101-year-old female patient with a non-ST segment elevation myocardial infarction. Coronary angiography showed a total occlusion of the proximal right coronary artery (RCA), and a significant stenosis in the proximal to mid left anterior descending artery (LAD). Despite a very poor initial clinical status, a percutaneous coronary intervention was successfully performed for the total occlusion in the RCA. The LAD lesion was treated with medical therapy only, on account of the age and general condition of the patient. She was discharged after recovering to a good health status, free of chest pain or dyspnea. (Korean

Circ J 2012;42:355-359)

KEY WORDS: Centenarian; Myocardial infarction; Percutaneous transluminal coronary angioplasty.

\section{Introduction}

With an ever-increasing life expectancy, the population of the elderly is constantly growing. Cardiovascular disease (CAD) remains the biggest cause of morbidity and mortality in this age group." Because age itself is a definite high risk factor in CAD adverse outcomes, those of extreme chronological age are often excluded from clinical trials of CAD. Therefore, little is known about the management and outcomes of acute coronary syndrome (ACS) in this age group. Recent advancements in technology, procedural techniques and medical therapy have resulted in improvement of percutaneous

Received: September 6, 2011

Revision Received: September 30, 2011

Accepted: October 11, 2011

Correspondence: Myung Ho Jeong, MD, The Heart Research Center of Chonnam National University Hospital, Cardiovascular Research Institute of Chonnam National University, 42 Jebong-ro, Dong-gu, Gwangju 501757, Korea

Tel: 82-62-220-6243, Fax: 82-62-228-7174

E-mail:myungho@chollian.net

- The authors have no financial conflicts of interest.

This is an Open Access article distributed under the terms of the Creative Commons Attribution Non-Commercial License (http://creativecommons. org/licenses/by-nc/3.0) which permits unrestricted non-commercial use, distribution, and reproduction in any medium, provided the original work is properly cited. coronary intervention (PCl) outcomes and enable the possibility for the elderly to undergo $\mathrm{PCl}$. There are many reports of successful $\mathrm{PCl}$ in octogenarians or nonagenarians. However, there are few such reports of centenarian patients with ACS. Performing PCl in a centenarian patient is extremely challenging. Here we report a case of a 101-year-old female patient with a non-ST segment elevation myocardial infarction (NSTEMI) who underwent a successful PCI.

\section{Case}

A 101-year-old female, with a history of hypertension and an old cerebellar infarction, was admitted to the Chonnam National University Hospital emergency room with complaints of sudden onset resting dyspnea. She had no history of dyslipidemia, diabetes mellitus or cardiac problems. On arrival, the patient's heart rate was a $150 \mathrm{bpm}$ and her blood pressure was 70/40 mm Hg. The electrocardiography (ECG) showed a sinus tachycardia and ST-segment depression in leads V 4-6 (Fig. 1). Initial serum levels of creatine kinase-MB and Troponin I were $98.3 \mathrm{U} / \mathrm{L}$ and $8.9 \mathrm{ug} / \mathrm{L}$, respectively. Serum levels of D-dimer and FDP were slightly elevated at 0.25 $\mathrm{mg} / \mathrm{L}$ and $5.6 \mathrm{ug} / \mathrm{mL}$. A chest X-ray revealed cardiomegaly and bilateral pulmonary edema. We considered NSTEMI or an acute pulmonary embolism (PE), based on clinical impression. To rule out $P E$, a chest CT angiogram was performed which showed no evidence 




Fig. 1. The electrocardiography shows a sinus tachycardia and ST-segment depression in leads V 4-6.
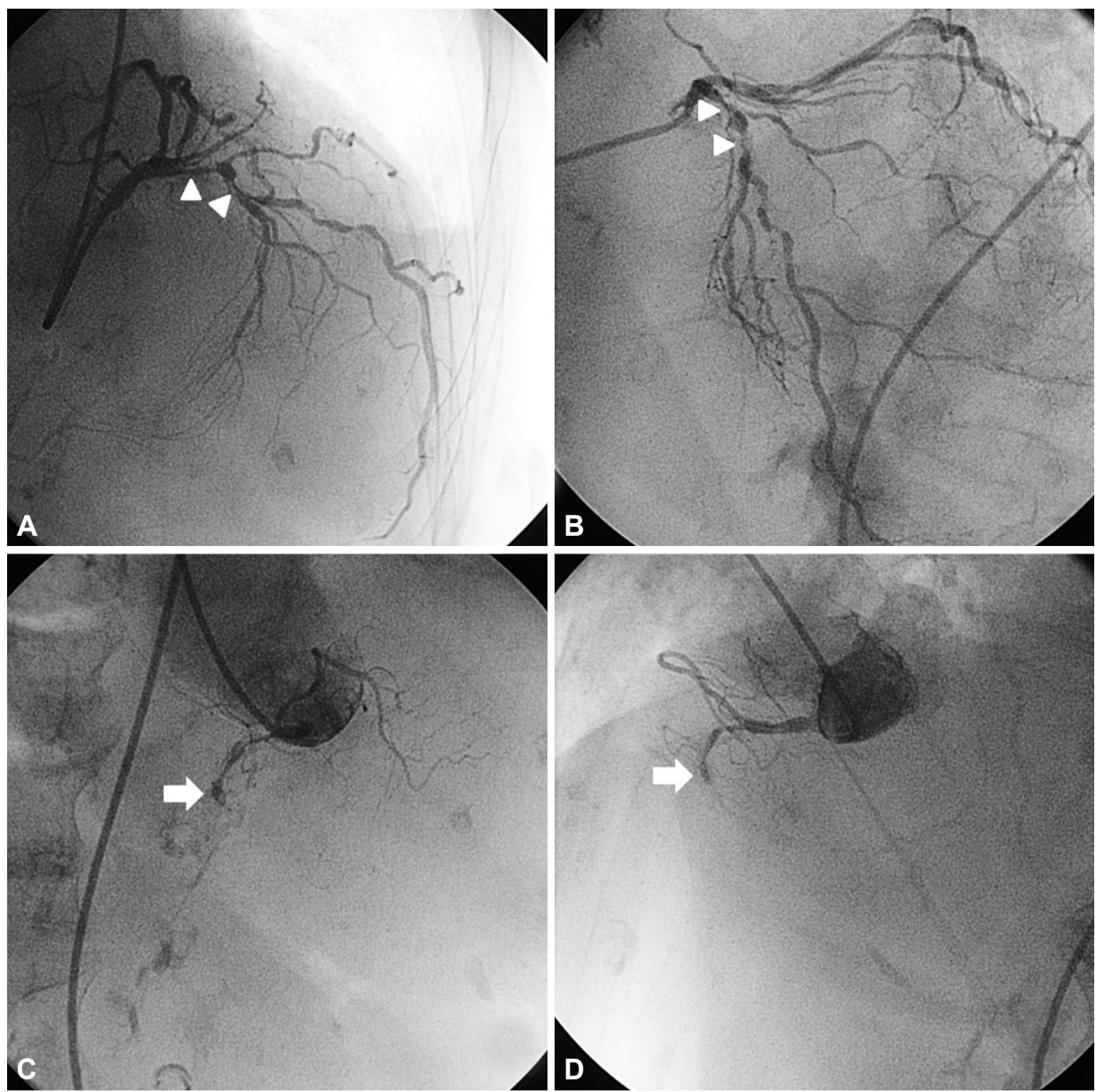

Fig. 2. Coronary angiography shows a significant stenosis of the proximal to mid left anterior descending artery (arrowheads) (A and B) and total thrombotic occlusion of the proximal right coronary artery (arrow) (C and D). 

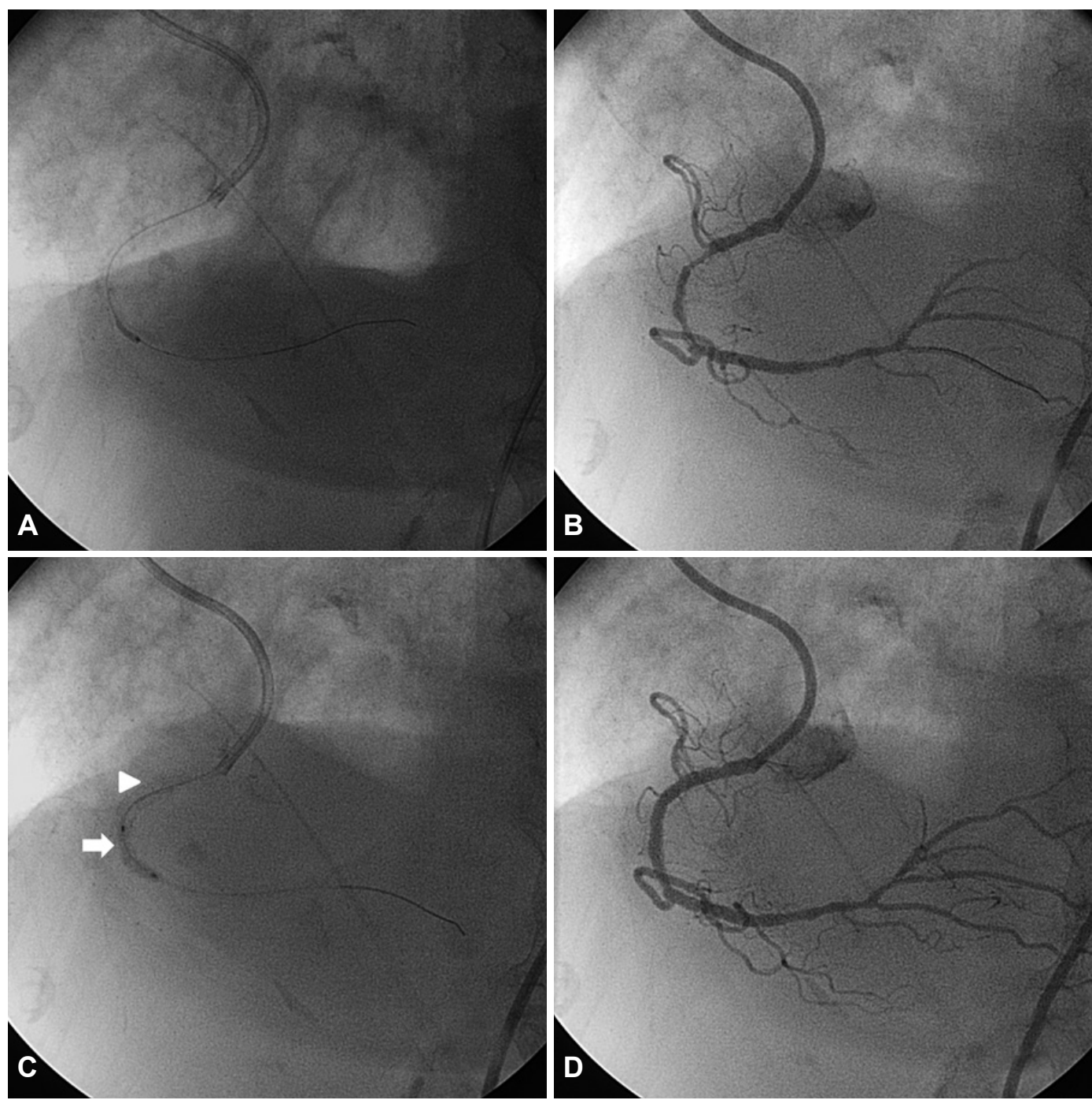

Fig. 3. Balloon angioplasty using a $1.5 \times 13 \mathrm{~mm}$ balloon was performed in the proximal and mid RCA (A and B). Subsequently, a $2.75 \times 23 \mathrm{~mm} B i 0-e n g i-$ neered R stent (Genous ${ }^{\mathrm{TM}}$ ) was deployed in the proximal RCA (C, arrow head), accompanied by a $2.75 \times 23 \mathrm{~mm}$ bare metal stent (Coroflex blue $\left.{ }^{\circledR}\right)$ in the mid RCA ( $C$, arrow). The final coronary angiography shows a good distal flow, without any residual stenosis (D). RCA: right coronary artery.

of PE. With the aid of artificial ventilation and medical therapy for the pulmonary edema, stabilization of the vital signs was achieved. However, Troponin I levels subsequently increased to $53.1 \mathrm{ug} / \mathrm{L}$. On the basis of a NSTEMI diagnosis, the patient was immediately sent to the catheterization laboratory.

Coronary angiography (CAG) demonstrated total thrombotic occlusion in the proximal right coronary artery (RCA) and significant stenosis in the proximal to mid left anterior descending artery (LAD) (Fig. 2). For the proximal RCA lesion, percutaneous coronary intervention using a $1.5 \times 13 \mathrm{~mm}$ balloon was performed, but some residual stenosis remained after the procedure. Then a $2.75 \times 23 \mathrm{~mm}$ bio-engineered $R$ stent (Genous ${ }^{\mathrm{TM}}$ bio-engineered $\mathrm{R}$ stent) was deployed in the proximal RCA, accompanied by a $2.75 \times 23 \mathrm{~mm}$ bare metal stent (Coroflex blue ${ }^{\circledR}$, B. Braun, Berlin, Germany) implantation for the mid RCA. Final CAG showed good distal flow and no residual stenosis in the RCA (Fig. 3). The LAD lesion was left to be treated after intensive medical therapy and stress testing, such as M-SPECT. No reperfusion arrhythmias, such as an accelerated idioventricular rhythm, were developed during PCI. The post-PCI ECG showed less ST-segment depression in leads V 4-6 compared to the pre-PCI ECG (Fig. 4). With the coronary care unit care, the patient's condition stabilized and complaints of chest pain and dyspnea disappeared. A follow-up ECG showed a considerable improvement of left ventricle systolic function, increasing from 49\% to 59\%. In light of her age and the improvement of her clinical status, our medical team decided to abandon the stress test and continue treatment with medical therapy only. Because of a residual high platelet reactivity of 319 platelet reaction unit (PRU), she was discharged on triple anti-platelet therapy (Aspirin 100 mg, Clopidogrel 75 mg, Cilostazol $200 \mathrm{mg}$ ). She is currently under follow up at 


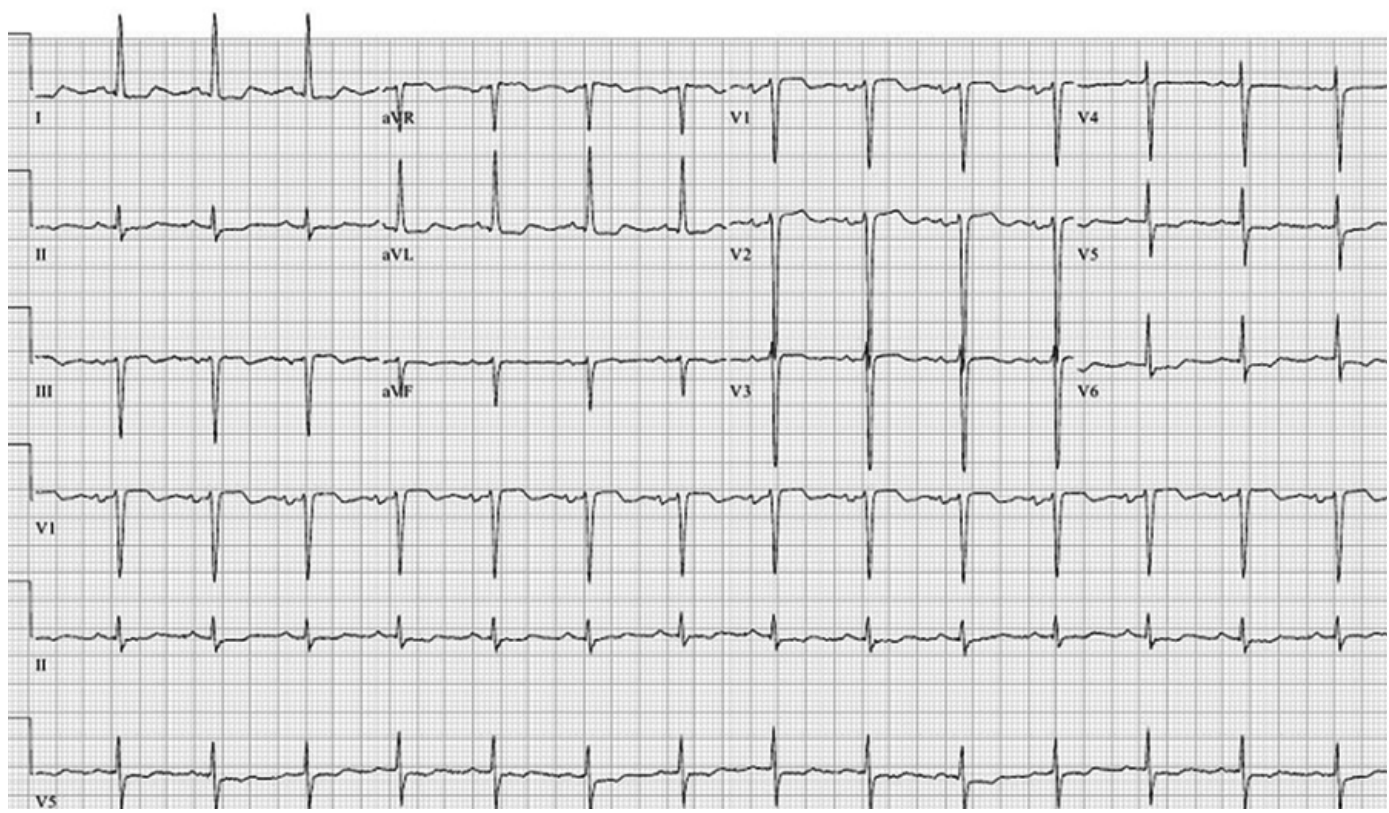

Fig. 4. The post-PCl electrocardiography shows less ST-segment depression in leads V 4-6, compared to pre-PCl. PCl: percutaneous coronary intervention.

the outpatient clinic and remains in good condition.

\section{Discussion}

Although advanced age is not a contraindication for $\mathrm{PCl}$ in patients with ACS, it poses a bigger challenge for the intervention team. The main reasons for this are comorbidities and peri-procedural complications, which are much more frequent at an extremely old age. Also, the elderly have more complex coronary lesions. ${ }^{23)}$ To the best of our knowledge, this case presents the first successful $\mathrm{PCl}$ in a centenarian patient with acute myocardial infarction in Korea.

The elderly usually have more comorbidity such as diabetes mellitus and hypertension, reduced cardiac and overall physiologic reserves and more complex coronary artery lesions. ${ }^{4-7)}$ These explain the high mortality among the elderly. Centenarians and nonagenarians display different clinical characteristics compared to younger elderly populations. ${ }^{2)}$ Both groups have a higher prevalence of ACS, but centenarians and nonagenarians are less likely to be diabetics, smokers or obese. This has been proposed as one of the reasons for successful aging in centenarians. ${ }^{8)}$ Our case subject did have hypertension, however, she never had dyslipidemia, diabetes mellitus or cardiac problems. Her lipid profiles at admission were within normal range, without the use of any lipid lowering medication. This favorable cardiovascular risk profile may very well play an important role in the patient achieving an age of over 100 years.

The patient had an old cerebellar infarction; which had occurred 8 years before. Despite the use of an angiotensin converting enzyme inhibitor and Clopidogrel since the incident, the patient developed a NSTEMI. Clopidogrel resistance tests showed a score of 319 PRU, indicating drug resistance. Therefore, triple antiplatelet therapy (Aspirin, Clopidogrel and Cilostazol) was prescribed, to overcome platelet resistance and protect against further cardiovascular events. However, triple anti-platelet therapy poses a potential problem: it may be associated with a significantly increased risk of bleeding in centenarians. ${ }^{2) 3}$ Instead of drug-eluting stents, a bio-engineered $\mathrm{R}$ stent and a bare-metal stent were implanted to reduce this risk of bleeding on long-term anti-platelet therapy. We expect to utilize new kinds of anti-platelet drugs such as Prasugrel or Ticaclelor in the future.

Old age is an important independent risk factor for $\mathrm{PCl}^{9}{ }^{9}$ The longterm outcome of $\mathrm{PCl}$ in the elderly is still controversial. In clinical practice, the elderly are more likely to undergo conservative medical therapy rather than $\mathrm{PCl}^{10-12)}$ For centenarians, this is especially true. ${ }^{2)}$ However, advancements in technology, procedural techniques, and adjunctive medical therapies are constantly improving procedural success rate and clinical outcome. ${ }^{4) 13)}$ The case we have presented serves as a testament to this progress. However, further clinical study is needed to prove the benefit of $\mathrm{PCl}$ in centenarians.

\section{References}

1. Avezum A, Makdisse $M$, Spencer $F_{1}$ et al. Impact of age on management and outcome of acute coronary syndrome: observations from the Global Registry of Acute Coronary Events (GRACE). Am Heart J 2005;149:67-73.

2. Skolnick AH, Alexander KP, Chen AY, et al. Characteristics, management, and outcomes of 5,557 patients age $>$ or $=90$ years with acute coronary syndromes: results from the CRUSADE Initiative. J Am Coll 
Cardiol 2007;49:1790-7.

3. From AM, Rihal CS, Lennon RJ, Holmes DR Jr, Prasad A. Temporal trends and improved outcomes of percutaneous coronary revascularization in nonagenarians. JACC Cardiovasc Interv 2008;1:692-8.

4. Batchelor WB, Anstrom KJ, Muhlbaier LH, et al. Contemporary outcome trends in the elderly undergoing percutaneous coronary interventions: results in 7,472 octogenarians: National Cardiovascular Network Collaboration. J Am Coll Cardiol 2000;36:723-30.

5. Floyd KC, Jayne JE, Kaplan AV, et al. Age-based differences of percutaneous coronary intervention in the drug-eluting stent era. J Interv Cardiol 2006;19:381-7.

6. Klein LW, Block P, Brindis RG, et al. Percutaneous coronary interventions in octogenarians in the American College of Cardiology-National Cardiovascular Data Registry: development of a nomogram predictive of in-hospital mortality. J Am Coll Cardio/ 2002;40:394-402.

7. Cohen HA, Williams DO, Holmes DR, et al. Impact of age on procedural and 1-year outcome in percutaneous transluminal coronary angioplasty: a report from the NHLBI Dynamic Registry. Am Heart J 2003; 146:513-9.
8. Galioto $A$, Dominguez $\sqcup$, Pineo $A$, et al. Cardiovascular risk factors in centenarians. Exp Geronto/ 2008;43:106-13.

9. Singh M, Rihal CS, Lennon RJ, Garratt KN, Mathew V, Holmes DR Jr. Prediction of complications following nonemergency percutaneous coronary interventions. Am J Cardiol 2005;96:907-12.

10. Lee SH, Chae JK. Long-term clinical outcomes of percutaneous coronary intervention using drug-eluting stents in octogenarians and older. Korean Circ J 2007;37:647-55.

11. Chung WS, Kim CJ, Seung KB, et al. Characteristics of coronary artery stenting in the elderly over 70 years old: short-term outcome and long-term angiographic and clinical follow-up. Korean Circ J 2001; 31:996-1003.

12. Lim SY, Jeong MH, Yang BR, et al. Long-term clinical outcomes after primary percutaneous coronary intervention in patients with acute myocardial infarction older than 75 years. Korean Circ J 2005;35:613-9.

13. Singh $M$, Rihal CS, Gersh BJ, et al. Twenty-five-year trends in in-hospital and long-term outcome after percutaneous coronary intervention: a single-institution experience. Circulation 2007;115:2835-41. 